\title{
Geotechnical Properties of Sediments by In Situ Tests
}

\author{
Sara Rios ${ }^{1(\bowtie)}$, António Viana da Fonseca ${ }^{1}$, Nuno Cristelo ${ }^{2}$, \\ and Claver Pinheiro ${ }^{1}$ \\ ${ }^{1}$ CONSTRUCT-GEO, Department of Civil Engineering, \\ Faculty of Engineering, University of Porto, Porto, Portugal \\ \{sara.rios,viana\}@fe.up.pt, clavergiovanni@gmail.com \\ ${ }^{2}$ Department of Engineering, CQVR, \\ University of Trás-os-Montes e Alto Douro, Vila Real, Portugal \\ ncristel@utad.pt
}

\begin{abstract}
River sediments are mainly composed by intermediate materials, between sand and clay, for which partial drainage conditions apply. In these cases, the interpretation of CPTU tests may be wrong since existing correlations are based on fully drained or fully undrained conditions. This paper presents results from CPTU tests performed in a river area to evaluate whether partial drainage conditions were observed. The results, presented in terms of the normalized velocity, show that great part of the analyzed profiles are in this condition. For this reason, the angle of shearing resistance was presented as a conservative estimate of the soil strength in these areas.
\end{abstract}

\section{Introduction}

Harbors management involves the execution of dredging operations to overcome excessive deposition of sediments in the harbor's basin and channel accesses, ensuring proper navigability conditions. Sediment disposal management depends on the nature of the dredged materials, which generally comprises fine materials such as sand (particles dimensions in the range of 0.2 to $0.06 \mathrm{~mm}$ ), silt (between 0.06 and $0.002 \mathrm{~mm}$ ) and clay (below $0.002 \mathrm{~mm}$ ). For that reason, a proper in situ geotechnical characterization of such sediments is necessary before a dredging operation. While the geotechnical behavior or sands and clays is relatively well understood with very well established assumptions (e.g., usually drained response and use of effective stress parameters for sand and, undrained response and undrained shear strength for clays), intermediate materials such as silts and various mixtures with sand and clay, that occur naturally and are frequently found worldwide, violate such assumptions. Behavior of intermediate soils (including sands with fines) can be transitional between sands and clays or can exhibit unique behavior that differs from both sands and clays. As a result, a given intermediate soil may simultaneously exhibit properties like a sand, while other properties may be more similar to a clay.

In particular, the extent to which penetrometer testing occurs under drained, undrained or intermediate conditions depends on the soil consolidation characteristics relative to the penetration rate and size of the penetrometer (Finnie and Randolph 1994). 
For that reason, a reliable evaluation of the mass permeability is a preliminary requirement for interpretation of piezocone (CPTU) tests (Randolph and Hope 2004; Schneider et al. 2007; Kim et al. 2008; DeJong and Randolph 2012; Mahmoodzadeh and Randolph 2014). As reported by Schnaid et al. (2004), for soils with permeability in the range of $10^{-5}$ to $10^{-8} \mathrm{~m} / \mathrm{s}$, the simplest accepted approach of a broad distinction between drained (gravel and sand) and undrained (clay) conditions cannot be applied to the interpretation of in situ tests without a great deal of uncertainty. Implications are that the cone resistance varies with penetration rate depending on whether the soil is contractive or dilatant as defined by the state parameter framework proposed by Jefferies and Been (Jefferies and Been 2006). As reported by DeJong and Krage (2014), if the soil has a large positive state (state $>0.20$; signifying very loose conditions, i.e., contractive behaviour), in drained cone penetration, no excess pore pressure would develop, but the drained tip resistance would be relatively low since the soil is contractive. In undrained cone penetration large positive excess pore pressures would be generated, which reduces the effective stress in the soil, and hence reduces the cone tip resistance relative to the drained tip resistance $\left(\mathrm{q}_{\mathrm{un}}<\mathrm{q}_{\mathrm{dr}}\right.$ ). If the state is highly negative (state $<-0.20$; dense conditions; i.e., dilatant behaviour) in drained cone penetration, this would again result in no development of excess pore pressures, but the magnitude of the drained tip resistance would be much higher than for the loose condition. In undrained cone penetration negative excess pore pressures would develop, increasing the effective stress, and making the undrained tip resistance higher than the drained tip resistance $\left(\mathrm{q}_{\mathrm{un}}>\mathrm{q}_{\mathrm{dr}}\right)$.

This means that for the standard penetration rate, a partial drainage in a loose soil would result in lower estimation of the soil strength relative to a fully drained condition, and a higher estimation of the soil strength relative to a fully undrained condition. Consequently, for the soil layers identified by the Robertson (2009) unified approach as "sands", the soil resistance generally evaluated by the angle of shearing resistance will be underestimated if partial draining conditions occur due to the presence of fines. On the contrary, for the soil layers identified as silts and clays, where the undrained strength would generally be used, an overestimation of this parameter will occur in partial draining conditions.

Discussion of this topic will be made in this paper for the specific case of CPTU tests in river sediments of a harbor site.

\section{Test Site and Procedures}

The study area is near the city center of Vila do Conde, in north Portugal, located in the left bank of Ave river where the new shipyards of Vila do Conde were installed. This area is very close to the river mouth as indicated in Fig. 1, which means that it suffers from the tidal influence. In fact, the tides in this region of the Atlantic coast are very wide frequently achieving a difference of $4 \mathrm{~m}$ of water height between the low and high tide. This had an important effect not only in the tests execution but also in the water table evaluation. Since the tests were performed on shore in an area that was only dry (and accessible) on the low tide the hour to perform the tests had to be judiciously chosen and there was no time for unexpected problems. Moreover, the water table depth, very useful in the interpretation of pore pressure measurements in CPTU tests, 


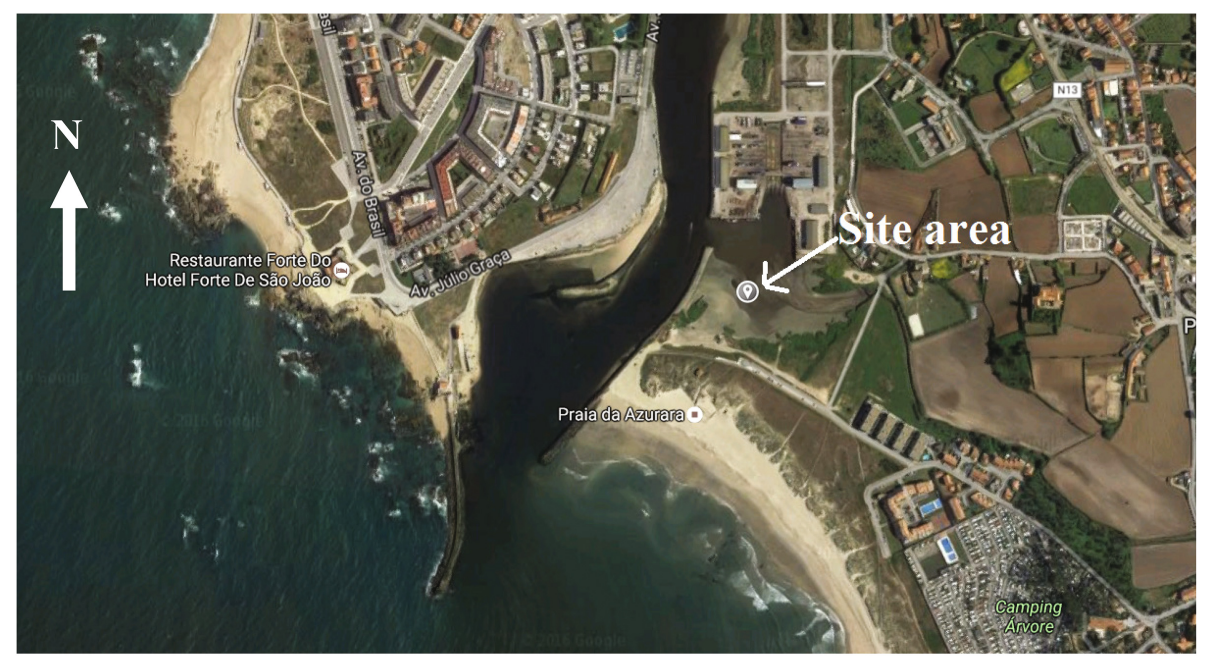

Fig. 1. Site area satellite view (Google maps: https://www.google.pt/maps/@41.3403005,-8. $7439096,1462 \mathrm{~m} /$ data $=! 3 \mathrm{~m} 1$ ! $1 \mathrm{e} 3$ )

was not constant throughout the tests. It is possible that it can also vary from layer to layer depending on the soil permeability, as less permeable layers take more time to reduce the pore pressures when the tide falls.

This area was chosen because it is a preferential area of sediment deposition, not only from Ave river but also from another small stream that converges to Ave river in this specific point. Unfortunately, it is not possible to see it in Fig. 1 because part of this stream is piped. On the other hand, this area was also a deposition place of dredged sediments from Ave river in the past due to the current need of assuring river navigability.

At this site three points were selected (Fig. 2), providing that they were all accessible in the low tide. In these points cone penetrometer tests (CPTU) were performed. The test procedure included first the execution of the light dynamic probing, followed by CPTU test until a maximum tip resistance (qc) of $20 \mathrm{MPa}$ was obtained since the aim was only to study the loosest layers of sediments. At the maximum depth, dissipation tests were performed but without success as the pore pressure remained constant. It can be argue that dissipation tests could have been performed at the higher excess pore pressure but since the water table was quite difficult to evaluate, it was even more difficult to know the best depth to perform dissipation tests. After removing the cone penetrometer, the water table depth was measured in the hole left by the cone, which was used in the interpretation of CPTU tests although it does not adjusts to the data as it will be shown below. A simple auger was also used to extract some undisturbed samples for future analysis that are out of the scope of this paper. Notwithstanding, it is worth mentioning that by visual inspection the soil is mainly composed by sand with fines and in some parts the sand becomes darker with more cohesion as an indication that the amount of clay/silt particles increases. 


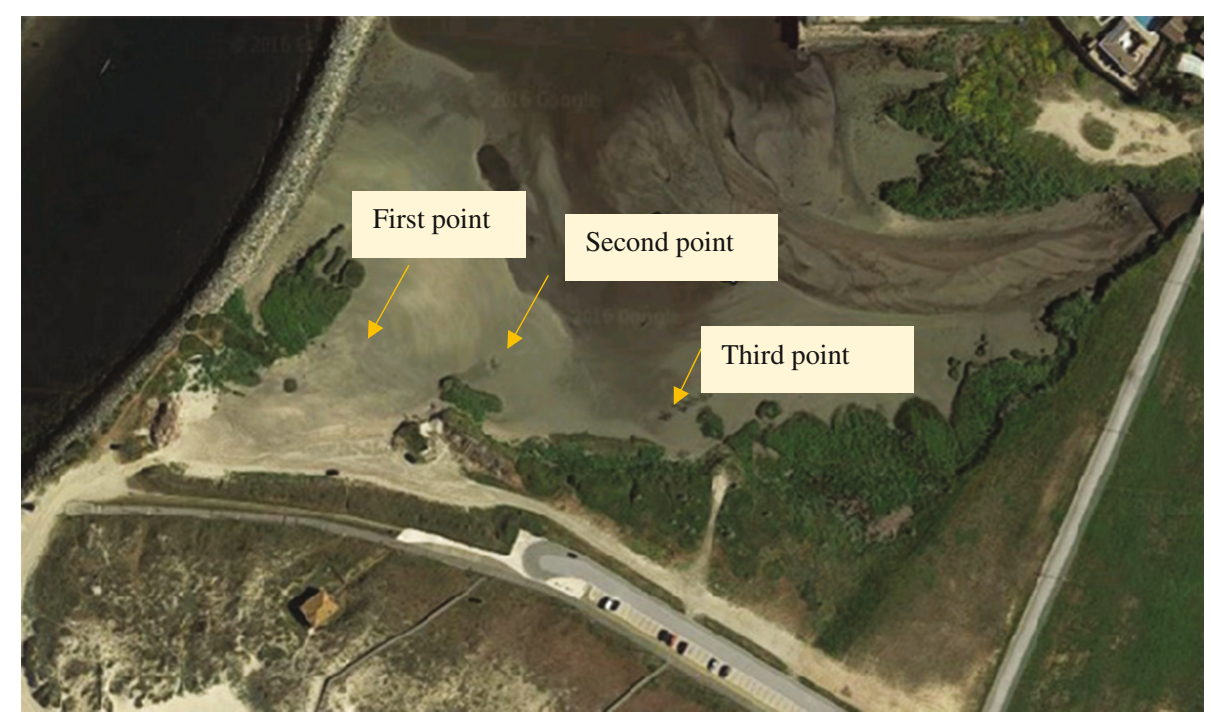

Fig. 2. Zoom of the site area with identification of the three test points

For the CPTU tests, a standard cone was used with a cone area of $10 \mathrm{~cm}^{2}$, a penetrometer diameter of $3.57 \mathrm{~cm}$ and a cone area ratio (a) of 0.58 . The tests were performed at the standard rate of $2 \mathrm{~cm} / \mathrm{s}$.

\section{CPTU Interpretation Methodology}

The tests were interpreted by the unified approach proposed by Robertson (2009) from the basic CPTU parameters $\left(\mathrm{q}_{\mathrm{c}}, \mathrm{f}_{\mathrm{s}}\right.$ and $\left.\mathrm{u}_{2}\right)$. However, the main expressions used to obtain some of the parameters will be identified here since there are several correlations proposed by different authors for the same parameter.

The soil unit weight $(\gamma)$ was evaluated by value obtained through expression (1) from Robertson and Cabal (2010):

$$
\frac{\gamma}{\gamma_{w}}=0.27 * \log (R f)+0.36 * \log \left(\frac{q_{t}}{p_{a}}\right)+1.236
$$

where,

$\mathrm{q}_{\mathrm{t}}$ is the corrected cone resistance as defined by Robertson $(2009): \mathrm{q}_{\mathrm{t}}=\mathrm{q}_{\mathrm{c}}+(1-\mathrm{a}) * \mathrm{u}_{0}$ $R_{f}$ is the friction ratio as defined by Robertson (2009): $R_{f}=f_{s} / q_{c}$

$\mathrm{p}_{\mathrm{a}}$ is the atmospheric pressure

$\gamma_{w}$ is the water unit weight 
The constrained modulus (M) was evaluated by one of the expressions proposed by Robertson (2009) as follows,

$$
M=\alpha_{M}\left(q_{t}-\sigma_{v 0}\right)
$$

where

$$
\begin{aligned}
& \alpha_{M}=Q_{t n} \text { when } Q_{t n} \leq 14 \\
& \alpha_{M}=14 \text { when } Q_{t n}>14
\end{aligned}
$$

The permeability coefficient (k) was obtained by expression (3) from Robertson (2010a),

$$
\begin{array}{ll}
k=10^{(0.952-3.04 * I c)} & \text { if } 1.0<\text { Ic }<3.27 \\
k=10^{(0.952-3.04 * I c)} & \text { if } 3.27<\text { Ic }<4.0
\end{array}
$$

Since it was not possible to evaluate the horizontal consolidation coefficient $\left(\mathrm{c}_{\mathrm{h}}\right)$ from dissipation tests, it was estimated by the consolidation theory according to Eq. (4) taking into account the constrained modulus (M) and the permeability coefficient $(\mathrm{k})$ obtained as described above:

$$
c_{h}=\frac{k * M}{\gamma_{w}}
$$

This enabled the calculation of the normalized velocity (V) as proposed by Randolph and Hope (2004) and DeJong et al. (2013), by expression (5) and Fig. 3.

$$
V=\frac{v * d}{c_{h}}
$$

where,

$\mathrm{v}$ is the cone penetration rate (in this case is the standard $\mathrm{v}=2 \mathrm{~cm} / \mathrm{s}$ )

$\mathrm{d}$ is the penetrometer diameter (is this case $\mathrm{d}=3.57 \mathrm{~cm}$ )

Note that according to Fig. 3, a standard rate of $2 \mathrm{~cm} / \mathrm{s}$ induces partial drainage conditions from fine sands through most silts.

In terms of strength parameters, the angle of shear resistance, can be obtained by the following expression proposed by Robertson (2010b) in function of the angle of shearing strength at critical state $\left(\phi_{\mathrm{cv}}^{\prime}\right)$ assumed $30^{\circ}$, 


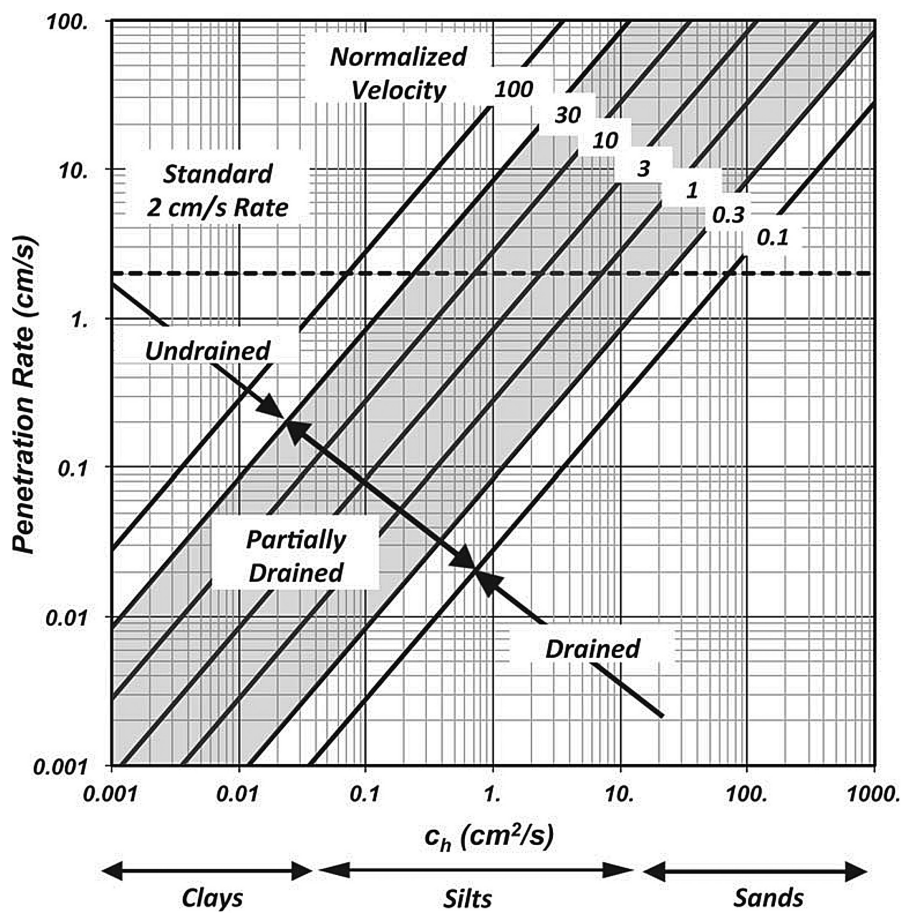

Fig. 3. Field decision chart for $10 \mathrm{~cm}^{2}$ cone presenting relation between coefficient of consolidation, penetration velocity and normalized velocity (DeJong et al. 2013)

$$
\phi^{\prime}=\phi_{c v}^{\prime}+14.44\left(\log Q_{t n, c s}\right)-22.31
$$

where,

$$
Q_{t n, c s}=K_{C} Q
$$

$$
\begin{aligned}
& K_{C}=1.0 \text { if, Ic }<1.64 \\
& K_{C}=5.581 \mathrm{I}_{\mathrm{C}^{3}}-0.403 \mathrm{I}_{\mathrm{C}^{4}}-21.63 \mathrm{I}_{\mathrm{C}^{2}}+33.75 \mathrm{I}_{\mathrm{C}}-17.88 \text { if, Ic }>1.64
\end{aligned}
$$

\section{Tests Results}

Figures 4, 5 and 6 present the obtained results for the three points indicated in Fig. 2. The water levels present (indicated as WT) are the ones obtained after removal of the penetrometer. On point 1 the soil is mainly composed by sand with fines and a few layers of silt. There is also clay between 3 and $4 \mathrm{~m}$ of depth. This point is the most affected by the dredged operations on the river, as it is close to the breakwater that separates the Ave river from the shipyards bay, so it is likely that the surface sand layers came from the river. On point 2 the surface layers are more silty while sand 

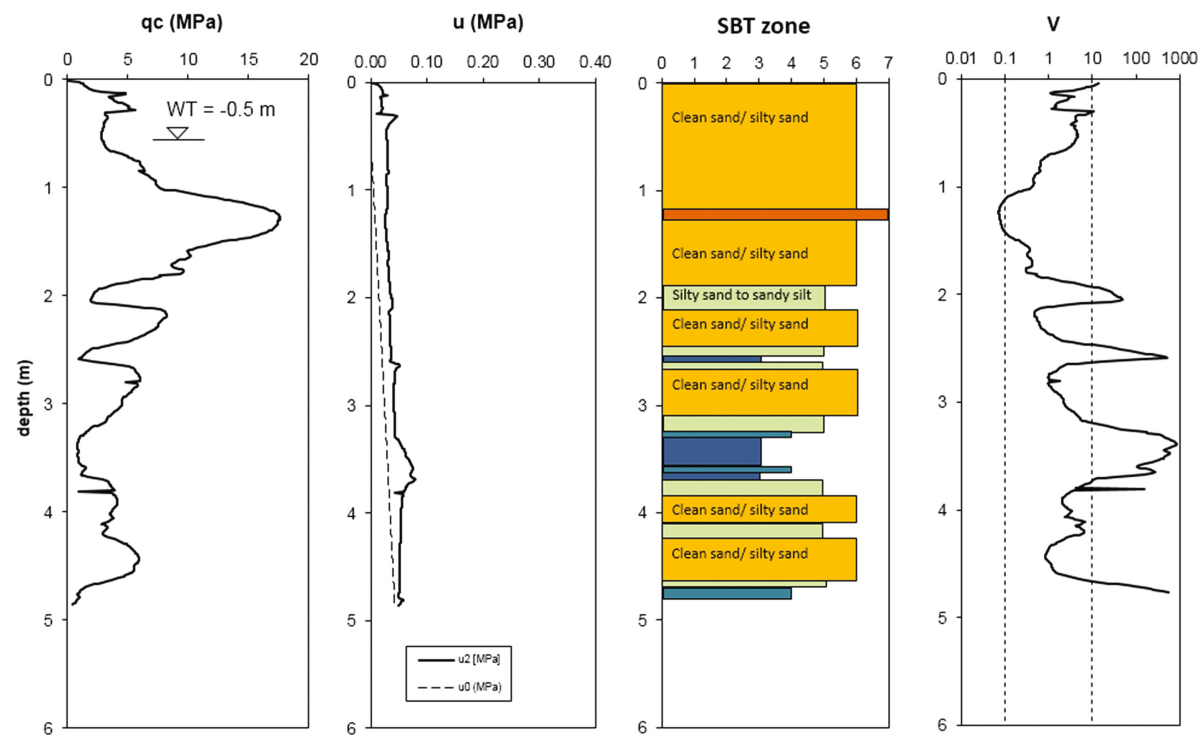

Fig. 4. CPTU test results for the first point
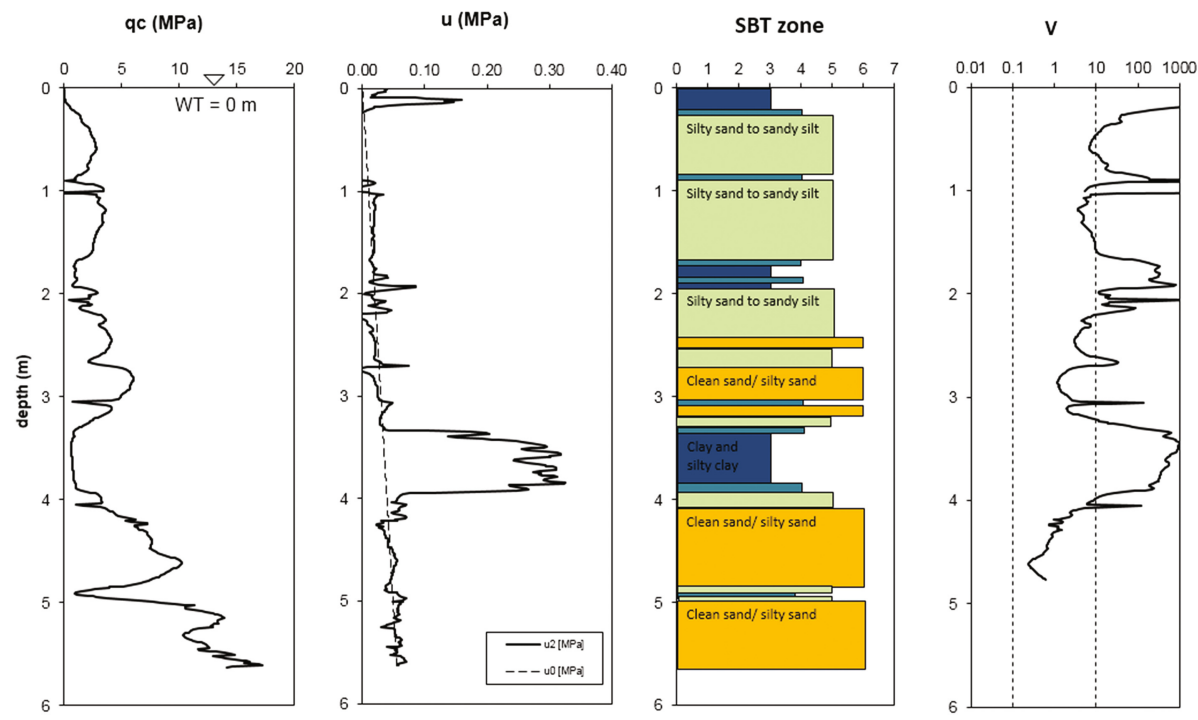

Fig. 5. CPTU test results for the second point

layers appear with depth. This point is the closest to the water in the bay and for that reason the water table is higher here. It is interesting to notice that both in points 1 and 2 the same clay layer appears between 3 and $4 \mathrm{~m}$ of depth. The third point, located near old wood piles (possibly used in a previous small pier), shows an intercalation of sand and silt layers. 

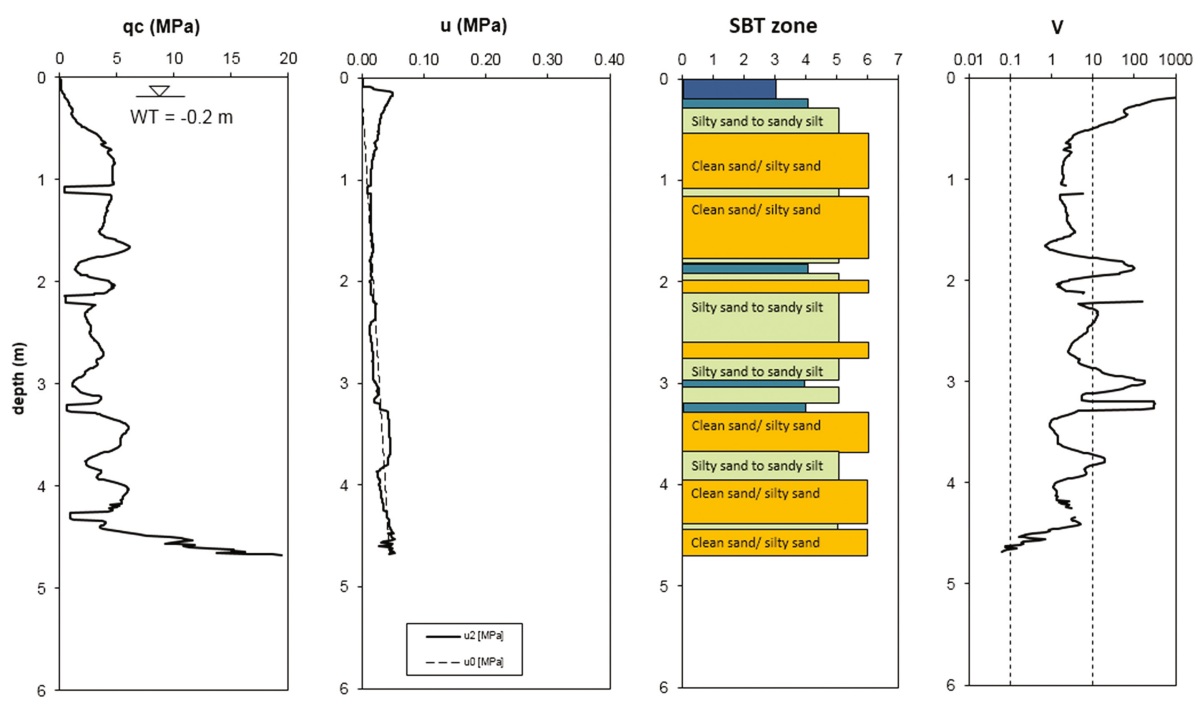

Fig. 6. CPTU test results for the third point

When the normalized velocity is computed it is observed that a significant part of the tests profiles has normalized velocities between 0.1 and 10 , which are associated with partial drainage conditions according to Schnaid et al. (2004), Schneider et al. (2008), DeJong et al. (2013). This means that with exception of some layers of finer soils for which undrained conditions could be acceptable without major errors, the soil (mainly in point 1 and 3) has an intermediate behavior. Since the estimation of the angle of shearing resistance (assuming fully drained conditions) corresponds to a conservative estimation of the soil strength according to the explanation presented in

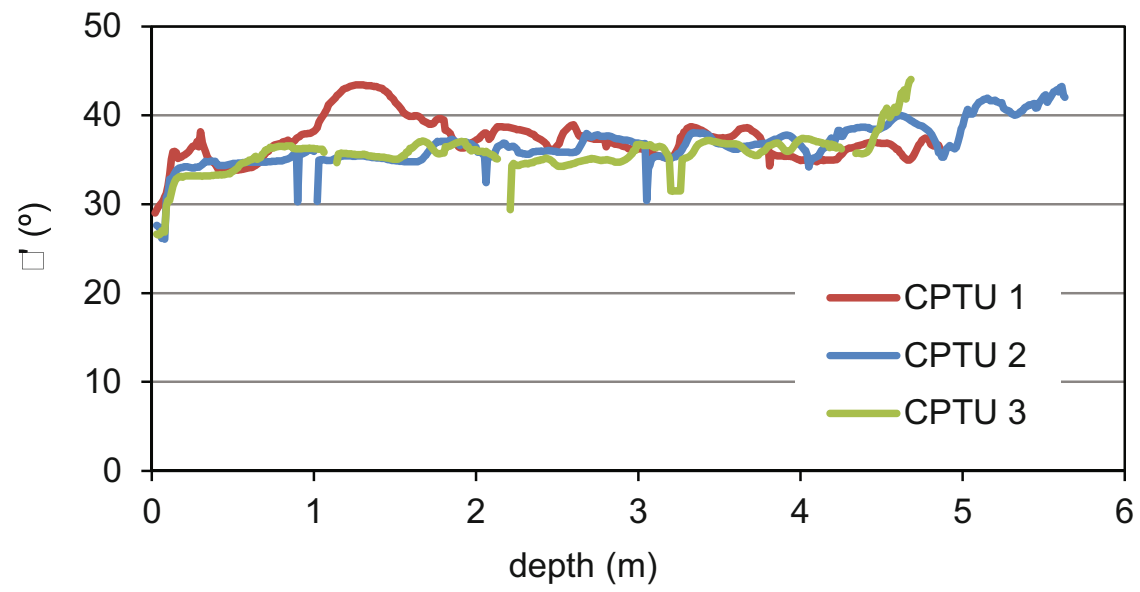

Fig. 7. Angle of shearing resistance profiles: (a) first point; (b) second point; (c) third point 
the introduction section of this paper, these profiles were plotted in Fig. 7. It is clear that in these areas of intermediate soil behavior the angle of shearing resistance is between $35^{\circ}$ and $40^{\circ}$, which is a reasonable value for loose well graded sandy soils (Hough 1957).

\section{Conclusions}

This paper presents results from CPTU tests performed in a river area influenced by the tides and dredging operations. The main purpose was to evaluate the suitability of CPTU tests to evaluate the permeability and strength properties of river sediments composed mainly by intermediate materials between clay and sand. The normalized velocity proposed by Randolph and Hope (2004) showed that this is actually the case for the soil presented in this paper, since normalized values between 1 and 10 were found in a great part of the analyzed profiles, indicating partial draining conditions. Although laboratory tests are needed to verify the soil hydraulic and mechanical properties obtained in situ, it is possible that the obtained angle of shearing resistance between $35^{\circ}$ and $40^{\circ}$ is a safe estimation of the effective strength of this soil.

Acknowledgments. The authors would like to acknowledge the MCTES/FCT (Portuguese Science and Technology Foundation of Portuguese Ministry of Science and Technology) for their financial support through the SFRH/BPD/85863/2012 scholarship, which is co-funded by the European Social Fund by POCH program, the project CONSTRUCT (POCI-01-0145-FEDER-007457) funded by COMPETE 2020, and CNPQ (the Brazilian council for scientific and technological development) for its financial support in 201465/2015-9 scholarship of the "Science without borders" program.

\section{References}

DeJong, J.T., Randolph, M.F.: Influence of partial consolidation during cone penetration on estimated soil behavior type and pore pressure dissipation measurements. ASCE J. Geotech. Geoenviron. Eng. 138(7), 777-788 (2012). doi:10.1061/(ASCE)GT.1943-5606.0000646

DeJong, J.T., Jaeger, R.A., Boulanger, R.W., Randolph, M.F., Wahl, D.A.J.: Variable penetration rate cone testing for characterization of intermediate soils. In: Coutinho, R., Mayne, P. (eds.) Proceedings of the 4th International Conference on Site Characterization (ISC-4), Porto Galinhas, Brasil, pp. 25-42 (2013)

Finnie, I.M.S., Randolph, M.F.: Punch-through and liquefaction induced failure of shallow foundations on calcareous sediments. In: Proceedings of 17th International Conference on the Behavior of Offshore Structures, Massachusetts Institute of Technology, Boston, vol. 1, pp. 217-230 (1994)

Hough, B.K.: Basic Soil Engineering. Ronald Press, New York (1957)

Jefferies, M., Been, K.: Soil Liquefaction: A Critical State Approach. CRC Press, Boca Raton (2006)

Kim, K., Prezzi, M., Salgado, R., Lee, W.: Effect of penetration rate on cone penetration resistance in saturated clayey soils. ASCE J. Geotech. Geoenviron. Eng. 134(8), 1142-1153 (2008) 
Krage, DeJong: Variable penetration rate cone testing for liquefaction evaluation of sand with fines. U.S. Geological survey final technical report, Davis, California, USA (2014)

Mahmoodzadeh, H., Randolph, M.F.: Penetrometer testing: effect of partial consolidation on subsequent dissipation response. ASCE J. Geotech. Geoenviron. Eng. 138(7), 777-788 (2014). doi:10.1061/(ASCE)GT.1943-5606.0000646

Randolph, M.F., Hope, S.: Effect of cone velocity on cone resistance and excess pore pressures. In: Proceedings of International Symposium on Engineering Practice and Performance of Soft Deposits, Yodogawa Kogisha, Osaka, pp. 147-152 (2004)

Robertson, P.K.: Estimating In-Situ soil permeability from CPT and CPTu. In: 2nd International Symposium on Cone Penetration Testing, Huntington Beach, USA, May 2010 (2010a)

Robertson, P.K.: Estimating In-Situ state parameter and friction angle in sandy soils from CPT. In: 2nd International Symposium on Cone Penetration Testing, Huntington Beach, USA, May $2010(2010 b)$

Robertson, P.K.: Interpretation of cone penetration tests - a unified approach. Can. Geotech. J. 46, 1337-1355 (2009). doi:10.1139/T09-065

Robertson, P.K., Cabal, K.L.: Estimating soil unit weight from CPT. In: 2nd International Symposium on Cone Penetration Testing, Huntington Beach, USA, May 2010 (2010)

Schnaid, F., Lehane, B.M., Fahey, M.: In situ test characterization of unusual geomaterials. In: Viana da Fonseca, A., Mayne, P. (eds.) Proceedings of the 2nd International Conference on Site Characterization (ISC-2), Porto, Portugal, vol. 1, pp. 49-75 (2004)

Schneider, J.A., Lehane, B.M., Schnaid, F.: Velocity effects on piezocone tests in normally and overconsolidated clays. Int. J. Phys. Modell. Geotech. 7(2), 23-34 (2007)

Schneider, J.A., Randolph, M.F., Mayne, P.W., Ramsey, N.R.: Analysis of factors influencing soil classification using normalized piezocone tip resistance and pore pressure parameters. ASCE J. Geotech. Geoenviron. Eng. 134(11), 1567-1586 (2008) 